\section{Novas perspectivas em políticas públicas educacionais: o percurso do município do Rio de Janeiro no atendimento socioeducativo em meio aberto}

\section{New perspectives on public policy education: the path of the municipality of Rio de Janeiro in socio-educational services in open environment}

\section{Resumo}

O Direito da Criança e do Adolescente apresenta como diretriz jusfilosófica, presente em texto constitucional, o princípio da Proteção Integral como orientador da definição de direitos e seu desdobramento em políticas públicas de atendimento à pessoa humana em fase peculiar de desenvolvimento. Esse atendimento universal especializa-se no Sistema de Garantias de Direitos, perpassando a proteção regular, a assistência à nova geração diante a violação de direitos e a tutela destinada a essa população quando em conflito com a lei, por meio de ato infracional. A medida socioeducativa surge como meio de reorientar o indivíduo submetido a ela, oportunizar a responsabilização pelo dano causado e promover um processo formativo-educacional com vistas à inclusão social. Este trabalho realiza um breve estudo sobre a Política de Atendimento Socioeducativo em Meio Aberto desenvolvida pelo município do Rio de Janeiro. O estudo concentra-se sobre a trajetória desenvolvida por esse ente federativo, desde a publicação da proposta até a implementação dessa política pública. A importância deste estudo faz-se pelo fato de ser nova competência municipal, contribuindo para o realizar políticas públicas para jovens em conflito com a com a lei, fundamento o direito à educação, orientado pelo fim de desenvolvimento integral da pessoa humana, infantoadolescente.

Palavras-chave: Direito da Criança e do Adolescente. Doutrina da Proteção Integral. Direito à Educação. Políticas Públicas. Medidas Socioeducativas em Meio Aberto.

\begin{abstract}
New Perspectives on Public Policy Education: the path of the Municipality of Rio de Janeiro in Socio-Educational Services in Open Environment. The Right of the Child and Adolescent jusphilosophical presents as a guideline, in this Constitution, the principle of Integral Protection as the guiding definition of rights and its impact on public policies that care for the human person in peculiar phase of development. This universal service specializing in the System of Warranties Rights protection regular assistance to the new generation on the violation of rights and protection aimed at this population when in conflict with the law, by means of an offense. The educational measure arises as a means of redirecting the individual subjected to it, nurture the responsibility for the damage caused and promote educational-training process aiming at social inclusion. This paper performs a brief study on the Socio-Educational Assistance Policy in Open Mode developed by the municipality of Rio de Janeiro. The study focuses on the trajectory developed by this federal entity, since the publication of the proposal to the implementation of this policy. The importance of this study it is because it is new municipal jurisdiction, helping to make public policies for youth in conflict with the law, the right to education foundation, guided by the purpose of development of the human person, infantoadolescente.
\end{abstract}

Keywords: Rights of Children and Adolescents. Doctrine of Integral Protection. Right to Education. Public Policy. Socio measures in Half Open. 


\section{Introdução}

É dever da família, da sociedade e do Estado assegurar à criança, ao adolescente e ao jovem, com absoluta prioridade, o direito à vida, à saúde, à alimentação, à educação, ao lazer, à profissionalização, à cultura, à dignidade, ao respeito, à liberdade e à convivência familiar e comunitária, além de colocá-los a salvo de toda forma de negligência, discriminação, exploração, violência, crueldade e opressão. ${ }^{2}$

Independentemente da origem ou da quantidade de verbetes, ambas as citações manifestam a preocupação das sociedades, que os originaram, para com a educação e tutela das novas gerações. Essa preocupação manifesta-se por meio da determinação de quem e em que momentos exerce tais funções nesta rede social. Em decorrência disso, é a mesma rede social que determina o que é necessário, indispensável à formação cidadã de cada novo integrante da comunidade, constituindo assim sistemas socioeducacionais, em sentido lato.

O presente trabalho pretende contribuir para a reflexão quanto à proposta educacional pública no que se refere à municipalização das medidas socioeducativas no município do Rio de Janeiro.

Inicialmente será apresentada uma breve exposição do fundamento teórico- metodológico que estrutura o Direito da Criança e do Adolescente: a Doutrina da Proteção Integral, o seu desencadear tanto na proposta de educação como direito fundamental e um dos instrumentos necessários à inclusão social; como também na estruturação do Estatuto da Criança e do Adolescente, código que regula esse direito especial, o atendimento a esta população, o que inclui a postura estatal perante o adolescente autor de ato infracional, e toda a política peculiar ao caso.

O desdobramento da política de atendimento chega à municipalização da execução das medidas socioeducativas, fenômeno recente no cenário nacional, e instituído no Rio de Janeiro em 2008. O percurso assumido por esse ente federativo, tanto no plano formal como no plano das implementações, é apresentado neste estudo por meio de trabalhos acadêmicos, expostos ao longo do trabalho. E por fim são destacados as fases desse caminho que ainda carecem de investimento e aperfeiçoamento para a melhora realização do programa e efetios ganhos na formação das juventudes - cidadã - que realizam parte significativa da vida da cidade maravilhosa.

\section{Da proteção integral ao direito fundamental à educação}

A nação brasileira, enquanto Estado Democrático de Direito, assumiu a Dignidade da Pessoa Humana como um de seus fundamentos. Essa matriz paradigmática ganha maior explicitação e desenvolvimento quando se refere à pessoa em fase peculiar de desenvolvimento: a criança e o adolescente ${ }^{3}$.

A família, da sociedade e do Estado, por meio de aspectos peculiares e interdependentes entre si, cada grupo (social e político) possuem responsabilidade solidária no atendimento dos direitos fundamentais destinados à juventude 4 .

De acordo com o posicionamento doutrinário atual, a promulgação dos direitos explícitos na carta constitucional, por meio do artigo 227, manifestam-se como os direitos fundamentais das juventudes, logo concentram as qualificações de serem inalienáveis, indisponíveis e intransferíveis.

E ainda presentes na relação do Estado com o indivíduo, quer seja por demandas de respeito, tolerância; ou ainda em situações de insuficiência do sujeito/família/ comunidade assegurar ao indivíduo tais bens imateriais, terá o Estado obrigação positiva de assegurar o exercício, por meio de diferentes posturas, como por exemplo, a instituição de um sistema especial de proteção, desenvolvendo nesta proteção especial mecanismos que tran-

De acordo coma professora Ana Paula de Barcellos, em sua obra A Eficácia Jurídica dos Princípios Constitucionais: O Princípio da Dignidade da Pessoa Humana, 2002, p. 26, "a dignidade da pessoa humana é um axioma jusfilosófico e, além disso, no nosso sistema de comando jurídico de superioridade hierárquica. A saber: as pessoas devem ter condições dignas de existência, aí incluindo-se a liberdade de desenvolverem-se como indivíduos, a possibilidade de participarem das deliberações coletivas, bem como condições materiais que as livre da indignidade".

$4 \quad$ CRFB/1988, artigo 227, caput: É dever da família, da sociedade e do Estado assegurar à criança, ao adolescente e ao jovem, com absoluta prioridade, o direito à vida, à saúde, à alimentação, à educação, ao lazer, à profissionalização, à cultura, à dignidade, ao respeito, à liberdade e à convivência familiar e comunitária, além de colocá-los a salvo de toda forma de negligência, discriminação, exploração, violência, crueldade e opressão. 
cendam a concepção de igualdade formal, e objetivem a igualdade material e substantiva do indivíduo através de ações afirmativas e transformativas, por exemplo.

A dignidade da pessoa humana como um valor jusfilosófico e um fundamento da nação, deve ainda perpassar as relações dos indivíduos entre si, de forma que em caso de violação aso direitos fundametais poderá incidir a intervenção do Estado Juiz.

Essa concepção tutelar sobre a infância e juventude, enquanto sujeito de direito, é construção epistemológica e social recente na mentalidade formal discursiva e adminstrativa do Estado brasileiro. Data-se do Estado formado em 1988. Construção que reflete um pouco o plano dos direitos humanos internacionais, por meio de promulgação de diferentes acordos e tratados internacionais $^{5}$ que manifestavam-se como uma nova forma de atendimento público e social a ser destinado a parte da população humana, buscando efetivar novas práticas políticas a partir desses fundamentos.

Associada às influências externas, há grande influência no plano interno junto ao Poder Constituinte originário de 1988, advindo de diferentes movimentos sociais que disputaram por representatividade, luta por reconhecimento e redistribuição de direitos a diversas parcelas da população até então mal atendidas ou negligenciadas pelo Poder Público.

Dogmaticamente, a República Federativa do Brasil trouxe ao documento político estatal a Doutrina da Proteção Integral, enquanto um corpo de princípios, diretrizes e regras, para ser o eixo paradigmático na política de atendimento de toda a infância e adolescência, independente das circunstâncias em que se encontram, tanto nas relações públicas como nas relações entre particulares.

No plano teórico tal postura possui caráter revolucionário ${ }^{6}$. Isso significa dizer que o Estado reconhece e

5 Os de maior relevância para este público alvo são: Declaração Universal dos Direitos Humanos, em 1948; Declaração dos Direitos da Criança, em 1959; e a Convenção Internacional sobre os Direitos da Criança, em 1989.

6 Cabe pontuar o motivo de tal qualificação. Antes dessa atual fase histórica, a atenção destinada à infância e juventude possuía outras referências. Incialmente, o primeiro tratamento destinado a esse público aconteceu pelo viés religioso, desenvolvido pela igreja católica. Essa orientação para atendimento à juventude pela sociedade civil, centrava-se para o público carente, e que não possuíam a formatação social de família vigente à época. Com o tempo outros atores sociais se incluem neste contexto, o que faz diminuir o tom religioso para o aspecto filantrópico. Já no século XX, tutela a pessoa humana que se encontra na fase de desenvolvimento infantil e na adolescência, enquanto sujeito de direitos universais, que necessita de atenção especial estatal, como também da sociedade e da família.

Uma manifestação prática no mundo jurídico advém desse contexto dogmático através da promulgação do Estatuto da Criança e do Adolescente, logo após a Constituição Republicana, em 1990. Enquanto legislação especial, tal norma destina-se a tutela indiscriminada dos cidadãos com idade cronológica inferior a dezoito anos. Esta proteção reafirma os direitos fundamentais da infância e juventude presente na carta magna, assim como estabelece sistemas de garantias próprios para a concretização destes por meio de políticas de atendimento.

Também advém desse fundamento constitucional a educação como um direito e prática social de todos e dever do Estado. A política educacional exposta na Carta Magna assume papel relevante na história pátria quando comparada a outras propostas assumidas nas constituições republicanas brasileiras ${ }^{7}$. Esse papel, no plano for-

mais precisamente em 1927, há a promulgação do Código de Menores, principal articulador foi o jurista de menores José Cândido de Albuquerque Mello Mattos. A segunda fase deste nível de atendimento à infantes e adolescentes é marcada pela edição do Código de Menores de 1979. Em ambos períodos em que o Estado formalmente agiu em favor desta parcela da população, que instrumentos legislativos e administrativos, destinou a uma clientela específica: menores em situação irregular de abandono ou delinquência juvenil, os quais destinavam a segregação, pois estes fugiam dos padrões sociais da época: o bom filho de família.

7 A Constituição de 1889 - A proclamação da república evidenciou a mudança paradigmática na gestão do governo do Estado, agora federado, que traz a separação entre igreja e Estado, liberdade de crença, casamento civil, direitos políticos, separação entre os poderes Executivo, Legislativo e Judiciário, consolidação do Estado Liberal através do exercício de liberdades manifestas pelos direitos de primeira geração. Sob a educação escolar, ao observar a obra desse mesmo mestre conclui que não houve definição por uma educação obrigatória, pois esta se relacionava ao esforço pessoal de cada individualidade (meritocracia), sem a obrigatoriedade do Estado na oferta de uma educação básica para todos; a gratuidade do ensino é deixada a cargo dos Estados federados; e o ensino apresenta-se como laico, quando ministrado nos espaços públicos. A Constituição de 1934 - A concepção de educação, manifesta nessa carta constitucional, revela a representação popular presente na sociedade brasileira naquele momento histórico nacional ao mesmo tempo em que há a permanência de características tradicionais da velha república, que evidenciam o espaço conflituoso e tenso da postura assumida pelo Estado. A Carta Constitucional de 1937 - esta atribui à família a responsabilidade pela educação integral da prole e ao Estado o dever de colaborar para a execução dessa responsa- 
mal, revela-se no cuidado de positivação pragmática de efetivação do direito a educação, que vai da determinação dos princípios que incidem sobre esse direito social fundamental até a determinação das garantias necessárias a execução das políticas públicas necessárias a promoção deste.

Em termos quantitativos, na história da República Brasileira, a carta constitucional de 1988 é a que mais possui dispositivos refrentes à educação. Nestes define que a educação é um direito de segunda geração, responsabilidade do Estado: União, Estados e Municípios em prestar o serviço, fundamentado nos princípios constitucionais e de acordo com a repartição de competência. Expressa ainda o quanto de sua receita cada ente deverá aplicar em sua rede educacional, e em caso de descumprimento este é um fator que poderá dar causa a intervenção política do ente federado.

Para além da reppartição de competências e vinculaçao de receiras para a operacionalização do direito em serviço educacional para a população, temos a importante qualificação pela política constitucional de ser este um direito público subjetivo.

Este reconhecimento pelo Estado brasileiro torna este ser políco responsável pela garantia e promoção do direito de forma ampla e genérica, a todo ser humano que se encontre sob a jurisdição brasileira (direito social), as-

bilidade. Mantém o ensino primário obrigatório e gratuito. Há continuidade do ensino religioso em todos os níveis de ensino, inserção da disciplina moral e cívica e o "adestramento físico" com finalidade de preparação para o cumprimento dos deveres da economia e da defesa nacional. É a primeira vez que o a constituição disciplina do ensino profissionalizante (prevocacional) destinado às classes menos favorecidas, e coube às indústrias e sindicatos econômicos a criação, na "esfera da especialidade, escola de aprendizes, destinadas aos filhos de seus operários ou de seus associados", estando o poder público regular tal ensino e promover subsídios para tais realidades A Carta Constitucional de 1946 - com a retomada da vivência democrática, esta carta manifestando os vieses liberais e democráticos, inspirados em textos constitucionais de proteção social assim como os movimentos sociais internos. Dessa forma a CRFB/1946 determina que o Estado é responsável por direitos sociais, tais como a educação, e de estabelecer garantias para a sua efetividade; além de legislar sobre diretrizes e bases da educação nacional. A Constituição de 1967 - no que se refere à educação percebe-se um retrocesso, pois esta passa a localizar-se no mesmo título da família e da cultura. São mantidas as responsabilidades do poder público em manter todos os níveis de ensino, a obrigatoriedade e gratuidade do ensino primário, vinculação orçamentária para a educação, e ensino religioso facultativo. sim como torna um direito da esfera pessoal (direito subjetivo, apreciado no caso concreto, perante o Poder Judiciário, para atendimento das especificidades da realidade que irá ser apreciada), necessário à formação humana e à convivência comunitária, profissional e cidadã, para a vida pós-moderna.

Essa postura do poder constituinte originário em reconhecer e positivar direitos, relacionados à infância e adolescência, possui uma importância histórica e jurídica fundamental, pois se revela como uma fonte real, de conteúdo jurídico indispensável a vida em coletividade, capaz de qualificar como humana a existência, possibilitar a promoção de inclusão social, além de expressar a positivação de lutas, ainda que com interesses diversos, de movimentos sociais, que mantém o empoderamento por meio do controle social quanto a efetivação, ou não, de tais direitos, afirmando assim a luta pela redistribuição de direitos.

Além dos fundamentos necessários para a relação entre o campo do reconhecimento e o campo da redistribuição de direitos, como afirma Fraser ${ }^{8}$, toda essa sistematização deixada pela Constituição delineou os parâmetros gerais de atuação no que se refere à tutela da juventude, e desencadeou a atuação do Estado na promoção de ações e programas de forma a dar efetividade ao direito fundamental à educação por meio de políticas públicas ${ }^{9}$. Um pouco da concretização dessa perspectiva é o que se passa a expor a seguir.

\section{O Estatuto da Criança e do Adolescente e as medidas socioeducativas}

Como já indicado acima, o Estatuto da Criança e do Adolescente (ECA) revelou-se como um documento cuja fundamentação advém de tratados internacionais, ratificados pelo Brasil e que promulgavam a Doutrina da Proteção Integral; e a Constituição da República Federativa do Brasil, proclamada em 1988.

Por ser um código especial, o microssistema instituído pelo ECA é o eixo orientador para regular os fatos

FRASER, Nancy. Reconhecimento sem ética? Lua Nova, São Paulo, v. 70, p. 101-138. 2007.

9 O termo aqui é empregado com o seguinte aspecto, referenciado na obra da professora Bucci, Maria P. Dallari, Políticas Públicas: ação coordenada do Poder Público destinada a dar impulso a máquina do governo, no sentido de realizar algum objetivo de ordem pública, p. 14. 
sociais desta matéria, por meio de princípios próprios, reconhecimento de direitos, orientação para a formulação de políticas de atendimento, medidas de proteção e acesso à justiça.

E é dentre as medidas protetivas que surgem as medidas socioeducativas. Questão não fácil de ser abordada, pois quando se pensa em juventude em conflito com a lei, um perfil surge na mente do homem médio brasileiro:

Adolescentes de 15 a 17 anos com famílias desestruturadas, defasagem escolar e envolvidos com drogas que cometeram, principalmente, infrações contra o patrimônio público como furto e roubo, ...

Esse perfil também foi o constatado pelo Conselho Nacional de Justiça, em pesquisa - Panorama Nacional: A Execução das Medidas Socioeducativas de Internação, publicada em abril/2012 ${ }^{10}$.

Essa realidade chega aos registros formais do sistema da medida socioeducativa, veiculada por relações estigmatizantes, e que responsabilizam predominantemente o indivíduo autor de ato infracional, além de negar o conflito histórico, legislativo, social, econômico, ideológico, educativo e político que tais dados quantitativos expressam objetivamente, e também qualitativamente de forma subjacente, aqueles que educaram o olhar para ver par além das informações frias.

Essa aversão ao conflito social, como afirmou Sou$\mathrm{za}^{11}$, é a construção simbólica de uma identidade coletiva em que permeia a ideologia da identidade nacional, formada a partir de generalidades que negam relações de poder que ao predominar promovem a dominação: cultural, ética, econômica, social e ideológica. Os conflitos sociais são naturalizados, e apenas apreendidos em seu aspecto subjetivo, mantendo o paradigma social inalterado, estigmatizando a juventude que não se qualifica como

10 Disponível na Internet http://www..cnj.jus.br/noticias/ cnj/18886:cnj-traca-perfil-dos-adolescentes-em-conflito-com-a-lei, consulta realizada em 08 de fevereiro de 2013. Cabe ressaltar que Estée o perfil que chega ao universo das medidas socioeducativas. É comum em relatos de agentes deste sistema a presença de histórias de jovens autores de ato infracional que por serem de ouro grupo socioeconômico, quando prestes a adentrarem ao sistema, são destes retirados devido a manobras escusas, ou não, realizadas por suas famílias e responsáveis, com a finalidade de não virarem notícia de nos meios de comunicação, por causa de "desvio" de conduta, e não autoria de ato infracional.

11 SOUZA, Jessé. A ralé brasileira: quem é e como vive. Belo Horizonte: UFMG, 2011. "bom filho de família" e sim como marginal, bandido, inimigo social, devendo ser submetido à sanção/vingança social, independente da forma em que esta venha a se manifestar. E assim, convenções, ideologias e estereótipos são mantidos continuamente.

Como pensar em redistribuição de direitos para a juventude, tendo a presente legislação como um dos instrumentos, diante dessa cultura de senso comum, conservador e reacionário, tão vivo nas práticas sociais e da administração pública? Como realizar redistribuição de direitos à parcela social que não conhece condições mínimas de existência digna? Como pensar em redistribuição de direitos para quem deveria ser reconhecido como sujeito de direitos e é nomeado como um problema social ${ }^{12}$ ?

O fundamento jusfilosófico que visa assegurar o direito à convivência comunitária estabelece como proposta ao autor de ato infracional ${ }^{13}$ à medida socioeducati$\mathrm{va}^{14}$. Esta por essência destina-se à promoção de processo educativo e de responsabilização para a vida em comunidade, e por esta estabelecido e promovido, evidenciando as possibilidades e limites dos fazeres individuais das juventudes, além de promoção de formação e qualificação com a finalidade de evitar o retorno dos jovens a situações de estado de conflito com a lei.

Assim a medida socioeducativa apresenta uma na-

12 Seu Jorge, Problema Social. "Se eu pudesse eu dava um toque em meu destino/Não seria um peregrino nesse imenso mundo cão/ Nem o bom que menino que vendeu limão/ Trabalho na feira pra comprar seu pão/Não aprendia as maldades que essa vida tem mataria/ A mina fome sem ter que roubar ninguém/Juro que nem conhecia a famosa funabem/ Onde foi a minha morada desde os tempos de neném/ é ruim acordar de madrugada pra vender bala no trem/ Se eu pudesse eu tocava meu destino/ Hoje seu seria alguém/ Seria eu um intelectual/ Mas como não tive chance de ter estudado em colégio legal/ Muitos me chamam de pivete/ Mas poucos me deram um apoio moral/ Seu pudesse eu não seria um problema social"

13 Artigo 103, ECA: considera-se ato infracional a conduta descrita como crime ou contravenção penal.

14 As modalidades de medida socioeducativa expressas pelo ECA somente terão seus objetivos explicitados através da legislação específica do Sistema Nacional de Atendimento Socioeducativo (SINASE, Lei 12. 594, de 2012, artigo $2^{\circ}$ ), promulgada doze anos depois, e são eles: 1 ) a responsabilização do adolescente quanto às consequências lesivas do ato infracional, sempre que possível a sua reparação; 2)a integração social do adolescente e a garantia de seus direitos individuais e sociais, por meio de seu plano individual de atendimento; e 3) a desaprovação da conduta infracional, efetivando as disposições da sentença como parâmetro máximo de privação de liberdade ou restrição de direitos, observados os limites previstos em lei. 
tureza constituitiva de duas dimensões. A primeira relacionada à sanção da conduta considerada pela comunidade como ilícita, e possibilita assim um marco delimitador do que socialmente é repudiado na vida em sociedade, as regras de conduta e valores que precisam ser respeitados, reciprocamente.

A outra dimensão refere-se a sua perspectiva educacional e pedagógica, em que o Poder Público oportuniza ao adolescente a reestruturação de uma nova prática social, permeada com a finalidade de uma educação que transcenda do sistema convencional, pelo qual, possivelmente, o jovem já tenha passado. Essa nova proposta diferencia-se do sistema penal proposto ao adulto, assim como as práticas estabelecidas em outros tempos históricos para adolescentes.

A medida socioeducativa só terá incidência a partir da execução de uma sentença judicial coercitiva, de acordo com as características da infração, a ser promovida pelo Poder Executivo, municipal ou estadual. A operacionalização da estrutura de funcionamento deste programa é determinada pelo governo federal, por meio do Sistema de Garantias de Direito (SGD).

Esse sistema de garantia de direitos constitui-se em políticas públicas integradas e orientadas por princípios e normas que regem a nova forma universalizante de atenção a crianças e adolescentes, cujas as ações são promovidas pelo Poder Público em suas três esferas de governo (União, Estados, Distrito Federal e Municípios), pelos três poderes (Executivo, Legislativo e Judiciário) e a sociedade civil, sob os eixos da Promoção, Defesa e Controle Social ${ }^{15}$.

Dentro do SGD, encontram-se diversos subsistemas que atendam situações peculiares, que incluem políticas sociais básicas, de assistência social, de proteção especial, saúde, educação, e de justiça voltados ao atendimento de crianças e adolescentes.

As normas gerais determinadas pelo ECA orientam para que o atendimento ocorra de forma articulada de ações governamentais e não governamentais, da União, Estados, Distrito Federal e Municípios ${ }^{16}$, sendo que a diretriz para essa atenção deva ocorrer por meio da municipalização de atendimento ${ }^{17}$.

15 De acordo com o posto em BRASIL. Sistema Nacional de Atendimento Socieducativo - SINASE. Presidência da República. Secretaria Especial dos Direitos Humanos. Brasília - DF: CONANDA, 2006. p. 22.

16 ECA, artigo 86.

17 ECA, artigo 88, I.
E assim o município ganha na Carta Constitucional de 1988 o status de ente federativo, com atribuições de promoção dos interesses locais, além de algumas outras competências comuns, concorrentes e exclusivas, também para promover o atendimento específico direcionado pelo ECA, priorizando o atendimento na localidade da infância e juventude.

A orientação advém da matiz constitucional de descentralização política e administrativa, com ênfase sobre os direitos sociais, que demandam atuação positiva do Estado para uma população específica. Essa postura, uma das conquistas populares do período redemocratização da nação, visa à descentralização gerencial e decisória, com participação da sociedade civil, de forma representativa na formulação de políticas e programas sociais, assim a instituição de controle interno, a ser exercido em cada órgão, ocorra o controle externo pelos Tribunais de Contas, e o controle social.

Nesse contexto de delineação da política de atendimento à infância e juventude é oportuno ressaltar dentre os subsistermas que integram ao SGD encontra-se o Sistema Nacional de Atendimento Socioeducativo (SINASE).

O SINASE é o

conjunto ordenado de princípios, regras e critérios, de caráter jurídico, político, pedagógico, financeiro e administrativo, desde a apuração do ato infracional até a execução de medida socioeducativa. Este sistema inclui os sistemas estaduais, distrital e municipais, bem como as políticas, planos, e programas específicos de atenção a este público. ${ }^{18}$

A presença e efetividade do SINASE acontece na vida de um adolescente quando este, pessoa com mais de doze anos e menos de dezoito anos realiza um ato infracional ${ }^{19}$, e será responsabilizado por suas ações, por meio de medida socioeducativa ${ }^{20}$, após decisão judicial com trânsito em julgado que decide o tipo de medida a ser aplicada.

BRASIL, 2006, p. 22.

19 De acordo com o ECA, artigo 103, ato infracional é a conduta descrita como crime ou contravenção penal.

20 A medida socioeducativa é a manifestação do Estado em resposta ao ato infracional praticados por adolescentes, cuja aplicação objetiva assegurar ao público-alvo oportunidade de reestruturação da vida, inibir a reincidência, desenvolvida com a finalidade educativa e pedagógica. A medida deve respeitar a capacidade do adolescente em cumpri-las, as circunstâncias em que o ato infracional foi praticado e a gravidade da infração. 
O tipo de medida socieducativa a ser aplicada é previamente definida no ECA, por meio do artigo 112. São elas: advertência, que consiste em uma admoestação verbal dada pelo juiz; reparação do dano, que se aplica em casos de dano ao patrimônio; prestação de serviço, que é a realização de um trabalho que possibilite outra forma do adolescente se relacionar com o grupo social, em que há possibilidade de oportunidades de aprendizagem para ambos; liberdade assistida, caracterizada no acompanhamento e orientação do adolescente que está em liberdade, no sentido de garantir seus direitos e sua inserção na rede de serviços locais; a semiliberdade, destinada a adolescentes para dormirem na instituição durante toda a semana, realizarem atividades educativas e pedagógicas a ele indicadas, e durante o fim da semana passam com suas famílias; e a internação em estabelecimento de educação que restringe a liberdade do adolescente, sendo este o último recurso a ser aplicável.

Dentro dessa classificação, há a divisão das medidas a serem cumpridas em meio aberto e meio fechado. As medidas a serem cumpridas em meio fechado, devido à gravidade da infração, semiliberdade e internação, são de responsabilidade do Estado, que no Rio de Janeiro, está submetida ao Departamento de Geral de Medidas Socioeducativas (DEGASE). Enquanto as medidas socioeducativas em meio aberto, prestação de serviço à comunidade e liberdade assistida, estão sob a responsabilidade dos municípios, desde 2006.

O percurso do Município do Rio de Janeiro no Atendimento Socioeducativo em Meio Aberto

Após breve apresentação das principais referências que circunstanciam a política de atendimento ao adolescente em conflito com a lei, cabe concentrar-se sobre a formação do sistema de medidas socioeducativas em meio aberto no município do Rio de Janeiro.

O processo de municipalização das medidas socioeducativas em meio aberto na cidade maravilhosa ocorreu a partir das normas estruturais estabelecidas pelo SINASE, em 2006, logo após a implantação do Plano Nacional de Assistência Social ${ }^{21}$ (PNAS/2004).

Essa medida reflete uma nova orientação na administração pública em descentralização de politicas públi-

${ }^{21}$ Cujas finalidades é o atendimento aos adolescentes em cumprimento de medida socioeducativa em meio aberto dentro da Proteção especial, a ser executada pelos Centro de Referência Especializados de Assistência Social (CREAS). cas de atendimento, para que o trato de assuntos relacionados ao cuidado imediato da população infantojuvenil seja promovido pelo governo local, princípio também comum a política de atendimento estabelecida pelo ECA.

O projeto piloto de Municipalização da Medidas Socioeducativas em Meio Aberto teve início no ano de 2008, foi implantado como uma política pública do município, passando a ser um programa da Secretaria Municipal de Assistência Social (SMAS).

Inicialmente, foi instituído em três Centros de Referência da Assistência Social (CRAS), como projeto-piloto promovido pela Secretaria Especial de Direitos Humanos do Governo Federal. Por meio da criação da Coordenação de Medias Socioeducativas houve o planejamento e instituição dos parâmetros da política municipal, e na sequência a ampliação para os demais CRAS do município.

Nesses espaços os adolescentes são atendidos por equipe multidisciplinar, formada por assistente social, pedagogo, advogado, psicólogo, agente comunitário e educador social. E o profissional que acompanha o adolescente no cumprimento da medida socioeducativa é denominado orientador.

O processo de atendimento inclui três etapas: acolhida, acompanhamento e finalização. Na etapa de acolhimento, dados gerais do adolescente são obtidos, estabelecimento de aproximação entre o orientador, o adolescente e a sua família, realização de atendimento individual e realização do Plano de Atendimento Individual (PIA).

Na etapa seguinte, o acompanhamento é desenvolvido por meio estudo de caso pela equipe multidisciplinar, continuidade dos atendimentos individuais; com as famílias com maior regularidade, realização de relatórios a serem enviados à Vara da Infância e Juventude e informação ao adolescente e sua família quanto ao alcance do processo de evolução no cumprimento da medida.

E o momento da finalização é expresso após a execução do PIA, apresentação de relatório ao juízo prolator da sentença de cumprimento de media socioeducacional. Após o cumprimento da medida socioeducativa o CRAS, ainda permanece disponível para atendimentos, de outra natureza caso o jovem e/ou sua família venha a precisar.

A realização do PIA caracteriza-se como o momento de subjetivação do direito à educação na medida socioeducativa. Instrumento oportuno para o Poder Executivo oportunizar oferta educativa de acordo com as 
singularidades e necessidades do adolescente, tendo este como um dos coparticipante deste processo educativo.

Uma peculiaridade conveniente ao destaque ${ }^{22}$ é a participação do Conselho Municipal de Direitos da Criança e do Adolescente ${ }^{23}$ junto ao grupo da Secretaria Municipal de Assistência Social na comissão responsável pela elaboração da Política Municipal de Atendimento Socioeducativo em Meio Aberto, enquanto representante da comunidade e órgão promovedor da política local.

No plano do discurso, a participação do Conselho Municipal de Direitos da Criança e do Adolescente revela ser uma legitimidade na representação dos direitos difusos e desenvolvimento da política local, no âmbito das medidas socioeducativas, e que revela uma determinada maturidade na formação de política pública para essa clientela no trato da questão.

A Política Municipal de Atendimento Socioeducativo em Meio Aberto é um documento aprovado pela Deliberação municipal ${ }^{24}$, apresenta-se como um produto de diálogo entre diferentes atores da administração pública local ${ }^{25}$ e representantes da sociedade civil organizada e militante na temática de direitos da infância e adolescência ${ }^{26}$.

Essa política apresenta-se como respeitando as diretrizes da descentralização político-administrativa e do cofinanciamento para assegurar recursos e ações para implementação. Estabelece meios de monitoramento, avaliação, orçamento, e o quadro operacional. Esse quadro

22 De acordo com LEAL, Roberta Martins dos Santos. Municipalização das medidas socioeducativas em meio aberto: efetivando direitos de adolescentes em conflito com a lei. 2011. Monografia (Pós Graduação Latu sensu) - Instituto A Vez do Mestre, Universidade Candido Mendes, Rio de Janeiro, 2011. p. 34.

23 O Conselho Municipal de Direitos da Criança e do Adolescente é um órgão deliberativo e controlador das ações políticas, públicas e privadas, de atendimento e promoção do bem estar social da criança e do adolescente no município. É uma instituição paritária, composta por membros da comunidade, e por representantes do poder público.

24 Deliberação municipal de número 879/11 AS/CMDCA. Disponível em: <http://www.ihn.org.br/uploads/deliberaca_87911.pdf >. Acesso em: 1 ago. 2013.

25 Como representantes do Poder Público local na participação da comissão de trabalhos temos: Secretaria Municipal de Assistência Social, Secretaria Municipal de Educação, Secretaria Municipal, Secretaria Municipal de Esporte e Lazer, Secretaria Municipal de Saúde e Secretaria de Segurança.

26 CEDECA-RJ - Centro de Defesa dos Direitos da Criança e do Adolescente, Organização de Direitos Humanos Projeto Legal, São Domingo Sávio, Instituto Homem Novo, e Associação Beneficente São Martinho. operacional divide-se em sete eixos, suporte institucional e pedagógico, educação, esporte/ cultura/ lazer, saúde, abordagem familiar e comunitária, profissionalização/ trabalho/ previdência, e diversidade étnica racial gênero e orientação sexual.

Cada um dos eixos possui um objetivo geral, objetivos específicos, ações, resultados esperados, determinação de prazo, responsável pela ação e parcerias. Busca-se ao fim tornar acessíveis direitos fundamentais, tais como reinserção e permanência na educação formal, ser atendido em programas de saúde, ter conhecimento e orientação dos serviços públicos disponíveis, como programas culturais destinados ao público em geral, na cidade maravilhosa.

De pronto, em uma observação rápida do documento legal que revela a política municipal de atendimento socioeducativo em meio aberto realizada pelo Rio de Janeiro, manifesta-se como uma ação direcionada a atender o jovem em cumprimento de medida socioeducativa, oferecendo-lhe o retorno à educação básica regular, o atendimento de saúde, acesso esporte, lazer e bens culturais. Dessa forma, ocupa-se o tempo livre dos meninos e garante-se o exercício de cidadania que até então, alguma parcela dessa juventude não conhecia, foram negados antes, e agora possibilitados por meio da mediação da sentença judicial condenatória.

Paralela a essa positividade tardia e às avessas ${ }^{27} \mathrm{de}$ exercício de direito público subjetivo à formação educacional e cidadã do jovem em cumprimento de medida socioeducativa, esse mesmo documento legal não traz consigo o conceito de educação que fundamenta suas práticas.

A ausência de objetividade quanto à concepção de educação escolhida e a pedagogia que norteará o processo socioeducacional é um risco perigoso no processo educativo, pois o espaço não ocupado pelo poder público em sua formação de políticas públicas educacionais, como dever do Estado de origem constitucional, com fundamento no desenvolvimento total ${ }^{28}$ do indivíduo e

27 Por meio de uma sentença judicial, de natureza sancionatória, os jovens têm acesso a direitos que ainda que reconhecidos, e regulamentados, não são de pronto disponíveis em plenitude a eles.

28 Desenvolvimento total é a proposta educacional de origem marxista, cuja a finalidade é a promoção de uma proposta educativa fundamentada no desenvolvimento completo, multilateral, em todos os sentidos das faculdades e das for- 
promovedor de dignidade da pessoa humana, permite que o lócus seja ocupado por qualquer outro objetivo. Objetivo este que pode até ser escuso ao processo educacional e executável por qualquer processo pedagógico, deste que apresente algum indício de boa vontade.

E em decorrência disso, fragiliza-se a essência educacional da medida socioeducativa, acirra-se situação de violência por parte do Estado para com o jovem sentenciado, por meio de nova negação de acesso à direitos, reforço estigmas sociais negativos quanto ao jovem em conflito com a lei, e mantém fortalecida a continuidade de ciclo de exclusão social de indivíduos em idade economicamente ativa, que não recebidos no sistema socioeconômico regular podem, sem esperanças, serem (re)cooptados pelo poder paralelo.

É assim que Estado social, fragmentado pelas políticas neoliberais, que fortalecem o estado mínimo, desloca para o seu "braço coercitivo" ${ }^{29}$ a qualificação social por meio socioeducacional, no plano da proposta de política de atendimento aos jovens em conflito com a lei.

Após a vista sob o plano formal da política por meio de trabalhos acadêmicos recentes, é possível perceber que ainda persistem algumas dimensões na condução dessa implementação de política de atendimento que carecem de relevante olhar da gestão administrativa, com vistas a trazer maior eficiência da proposta, assim como aproximar o plano das práticas cotidianas ao plano do discurso da proposta.

Essa realidade é relatada na apresentação do trabalho acadêmico de Menezes ${ }^{30}$; e Azevedo e Suçães ${ }^{31}$.

ças produtivas, das necessidades e capacidade da satisfação do indivíduo. Essa proposta educacional coloca-se de encontro a realidade de alienação humana, em que todo homem torna-se alienado por outro, e de sua própria natureza. Esse conceito é desenvolvido por MANACORDA, Mário Aligheiro. Marx e a pedagogia moderna. São Paulo: Cortez: Autores Associados, 1991.

29 O braço coercitivo do estado é apresentado LoÏc Wacquant, em Forjando o estado neoliberal: trabalho social, regime prisional e insegurança social. In: BATISTA, Vera M. (Org.) LoÏc Wacquant e a questão penal no capitalismo neoliberal. Rio de Janeiro: Revan, 2012.

30 MENEZES, Thaís Vargas. A responsabilidade do adolescente autor de ato infraccional: ampliando o horizonte a partir da proposta socioeducativa. 2012. $131 \mathrm{f}$. Dissertação (Mestrado em Psicologia) Universidade Federal do Rio de Janeiro, Rio de Janeiro, 2012.

31 AZEVEDO, Monique Silva de; SUÇÃES, Nathália Amaro. A municipalização das medidas socioeducativas em meio aberto no Estado do Rio de Janeiro. 2011. f. Trabalho de Conclusão de Curso (Graduação) Serviço Social, Univer-
Ambas as pesquisas centraram-se sob a perspectiva de uma pesquisa etnográfica ${ }^{32}$ e documental, observando em alguns CRAS do município do Rio de Janeiro os efeitos nos loci das práticas realizadas pelos agentes públicos e as conexões destes fazeres fundamentados em orientações políticas advindas do órgão superior no trato do atendimento aos jovens em cumprimento de medidas socioeducativas.

A partir do estudo de tais trabalhos foi possível identificar alguns dos aspectos na implementação e instituição da política de atendimento socioeducativo em meio aberto no Rio de Janeiro que necessitam de aperfeiçoamento em sua trajetória, para que na dimensão da realização prática-cotidiana permaneçam em consonância com a proposta municipal de atuação, que representa a dimensão do discurso oficial do ente municipal. A seguir, tais aspectos são ressaltados.

A localização dos CRAS pesquisados - os centros pesquisados estão localizados em regiões geográficas do município do Rio de Janeiro que não são alcançadas pela qualidade de "cidade maravilhosa". Pelos textos infere-se que a juventude atendida são os que se encontram em situação de risco social. De forma que a esses chegam a usufruir serviços que revelam-se como efetivação de alguns direitos sociais somente após serem submetidos a uma sentença judicial condenatória.

\section{A pedagogia presente na medida socioeducativa} desenvolvida pelo ente municipal - do texto que expressa

sidade Federal do Rio de Janeiro, Rio de Janeiro, 2011.

32 A pesquisa etnográfica apresenta e traduz a prática da observação, da descrição e da análise das dinâmicas interativas e comunicativas como uma das mais relevantes técnicas. Assim, ao se avaliar programas e projetos, visando à recomendação de soluções para os problemas e impasses identificados, deve-se levar em conta as evidências da observação e da descrição, elementos cruciais da atividade etnográfica. E, se é a partir dos encontros e relacionamentos que extraímos a compreensão e explicação das experiências humanas, que se dão no mundo da vida, no mundo do trabalho, no mundo do entretenimento e da arte, então, somente poderemos extrair as evidências necessárias para compreender os contextos destes relacionamentos, a partir das análises das dinâmicas que marcam esses encontros. A filosofia da pesquisa etnográfica repousa na "doutrina" que compreende a vida e a existência social como localizadas e resultantes no fato mais óbvio: o encontro e o relacionamento. E é nesse e desse encontro que emergem todas as formas de negociação, solidariedade, valores, redes, transmissão, trocas, simbologias e cerimônias, conflitos, compartilhamentos, etc. Disponível em: <http://www.proppi. uff.br/leeccc/pesquisa-etnogr\%C3\%A1fica>. Acesso em: 08 jul. 2013. 
a política municipal de atendimento socioeducativo em meio aberto um predomínio de interesse sobre o aspecto jurídico-legal sobre o pedagógico-educacional. Já de acordo com as exposições, não ficou evidente a existência, por parte do poder público municipal da proposta pedagógica a ser desenvolvida na execução da medida socioeducativa, marcada por um caráter intencional, coma a presença de práticas claras e definidas, com objetivos educacionais a serem alcançados, em transparência e acordo com o adolescente que chega ao espaço institucional.

Como exemplificador desse fato, cabe pontuar a ressalva realizada no trabalho de Menezes $^{33}$, em que a autora exterioriza a fala significativa de agentes, a dificuldade de manter a execução de medidas e de garantir a frequência dos adolescentes.

A medida socioeducativa não pode ser algo apenas para a satisfação de uma execução judicial. Tal prática imediatista torna-se simplória, e apenas capaz de satisfazer cumprimento de formalidades jurídicas, sem, contudo sensibilizar para que haja mudanças necessárias tanto no sujeito submetido a medida; como também aos agentes educadores, que agem em nome da coletividade. $\mathrm{O}$ ente municipal evidencia a existência de pedagogia para esse processo que diante das juventudes que lhe são encaminhadas, desempenham práticas frágeis para uma educação para mudança, e tais práticas explicam-se nas fragilidades do sistema.

Assim, sem explícita determinação no cotidiano do que se quer e onde se quer chegar a medida socioeducativa remanesce, mas sem alcançar de fato e junto aos adolescentes a sua natureza existencial.

Necessidade de diálogo intersetorial entre os órgãos do ente municipal e deste com a comunidade - a municipalização de medidas socioeducativas atende ao princípio da política de atendimento estabelecida pelo ECA, e a efetividade desse programa foi designada pelo poder federal na regulamentação das normas gerais e a Política Nacional de Assistência Social ofereceria a política de proteção social especial de média complexidade (como no caso de cumprimento de medidas socioeducativas) por meio das
MENEZES, Thaís Vargas. A responsabilidade do adolescente autor de ato infraccional: ampliando o horizonte a partir da proposta socioeducativa. 2012. f. Dissertação (Mestrado) Psicologia, Universidade Federal do Rio de Janeiro, Rio de Janeiro, 2012. p. 96. secretarias municipais de Assistência Social.

Assim, o cumprimento das normas gerais tem acontecido. A realização de programas educacionais não convencionais demanda a articulação dos diferentes olhares e intervenções na formulação de programas institucionais para que tenha futuro eficaz, sem perder de vista que tais investimentos são de médio e longo prazo.

Porém a cultura tradicional organizacional e administrativa das instituições orienta as práticas de gestão de forma segmentada, em que cada órgão/setor administrativo realiza seu mister funcional de forma predominantemente isolada. E o Estado quando apoiado nessas premissas relaciona-se com o particular e a comunidade em geral. Nos trabalhos essa dificuldade dialógica manifesta-se desde a interlocução entre os agentes presentes no CRAS"s até entre as secretarias municipais.

O fenômeno educacional para a juventude que transgride as convenções coletivas compreende uma proposta complexa que está a cargo solidariamente da sociedade política e sociedade civil. A proposta de enfrentamento dessas realidades não pode ser alcançada no agir solitário de um órgão administrativo municipal. Como expõe Habermas ${ }^{34}$, fazem-se necessárias no espaço da administração pública a construção e cultura da liberdade comunicativa, fundadas na relação intersubjetiva dos sujeitos, atores indispensáveis ao debate, a fim de que se alcance atos, posturas, programas e políticas públicas que satisfaçam a necessidade pública, evitem gastos de recursos materiais e imateriais desnecessários, assim como promovam a gestão participativa e democrática dos interesses da cidade, no que se refere à educação de seus cidadãos jovens.

Formação continuada para os agentes socioeducadores - os estudos apontam para uma preocupação inicial de formação para com as equipes que atuariam no processo de implementação da municipalização da execução de medidas socioeducativas. No entanto, com as necessidades cotidianas, essa preocupação não se manteve como inicialmente. De forma que as falas de alguns profissionais dos CRAS's surgem apresentando essa demanda. Veem-se as limitações funcionais diante as complexidades a serem enfrentadas no cotidiano de trabalho.

Outro destaque promovido está associado à des-

HABERMANS, Jurgen. Direito e democracia: entre a facticidade e a validade. Rio de Janeiro: Tempo Brasileiro, 2003. p. 156. v. 1. 
continuidade de alguns trabalhos devido ao vínculo que alguns agentes possuem com a administração, caracterizada por ser uma contratação temporária, que em sua maioria não ultrapassa um ano civil, e em alguns casos, ao invés de realizar a contratação pessoal o ente municipal promove convênios com Organizações Não Governamentais.

Tal realidade pode enfraquecer os laços de comprometimento por tais agentes com o programa em execução, ou então ligações intersubjetivas destes com os jovens no cumprimento de suas medidas, o que chega a proximidade de comprometer toda a efetividade da política, pois está presente a ruptura do trabalho em desenvolvimento, a qualquer momento.

A participação ativa do adolescente autor de ato infracional no cumprimento da medida - os adolescentes, autores de ato infracional, após a sentença judicial, são encaminhados ao CRAS, para o memento de execução da medida socioeducativa. Nesse momento, é constituído o plano de atendimento individual. Não consta nos estudos pesquisados que sejam estes chamados a participarem, de forma consciente e atuante da formação desse procedimento. A omissão desse dado pode ter sido algo não relevante para as pesquisadoras, mas também podem evidenciar uma postura do Estado, que enfraqueceria o processo de responsabilização e formação do indivíduo que agiu de forma ilícita, e precisa continuar sendo "partícipe", coautor na formulação e realização de seu processo socioeducativo.

A aplicação de uma política que se oriente pelo desenvolvimento humano, como já reconheceu Paulo Freire, é difícil, mas imprescindível para que o "formando" desde o princípio assuma-se como sujeito também da produção de saber, ou melhor, saberes necessários à satisfação das necessidades subjetivas e coletivas, fundados em preceitos da condição humana de inacabado, da vida em sociedade e da ética comunitária.

O respeito à autonomia e a dignidade de cada um é um imperativo ético e não um favor que podemos ou não conceder [...] Saber que devo respeitar à autonomia e a identidade do educando exige de mim uma prática em tudo coerente com este saber.. ${ }^{35}$

Acompanhamento e políticas educacionais e assis-

35 FREIRE, Paulo. Pedagogia da autonomia: saberes necessários à prática educativa. São Paulo: Paz e Terra, 1996. p. 66-67. tenciais após o cumprimento das medidas socioeducativas - essa última limitação, apresentada nos trabalhos, evidencia a necessidade de que alguns jovens e suas famílias necessitam de orientação e assistência até que se encontrem num nível de desenvolvimento e autonomia que consigam caminhar com segurança e sozinhos.

A partir dessa constatação é notório que a existência de políticas e programas sociais do Estado destinados tanto a juventude como a população em estado de risco social não efetivos por si só. Além da importância do reconhecimento de direitos sociais, políticas de implementação, acompanhamento e responsabilização dos beneficiários de tal política tornam-se necessários na continuidade do atendimento a assistência técnica temporária de determinados indivíduos. Tais práticas asseguram que direitos sociais sejam redistribuídos aos que deles precisam mesmo que em sua apresentação ínfima para existirem com um pouco mais de dignidade, condição essencialmente humana.

\section{Considerações finais}

A Proteção Integral, enquanto paradigma de atuação do Estado no que se refere a reconhecimento, redistribuição e a políticas públicas para essa população de crianças e adolescentes, no plano do discurso, garante a promoção da existência digna desses brasileiros.

Para melhor concretização da proposta política houve a descentralização do atendimento, compartilhando responsabilidades com os municípios, para que a infância e juventude tenham suas necessidades atendidas em sua própria comunidade.

A mesma orientação chega para a execução de medidas socioeducativas em meio aberto, destinadas aos adolescentes autores de ato infracional, e teve realização em 2008, na cidade maravilhosa.

Esse processo ainda que iniciado, não está plenamente concluído. No entanto, pela trajetória constituída foi possível identificar progressos e necessidades de aprimoramento.

Dentre os progressos, encontra-se o reconhecimento pelo Estado da necessidade de atenção e promoção peculiar à infância e adolescência. E para se chegar a essa conclusão basta apenas visitarmos os fundamentos da legislação anterior, em que a sociedade política apresentava-se apenas para uma pro- 
posta única de enquadramento ou restrição da vida coletiva dos que não tinham os pressupostos sociais ou econômicos necessários para serem considerados como "bons filhos de família". O reconhecimento da juventude como titular de direito é fundamento para os embates sociais na conquista de reconhecimento e subjetivação de direitos sociais, quer pelas vias da formulação de políticas públicas quer seja pela via da judicialização.

Outro avanço encontra-se na forma pela qual o município assumiu esta responsabilidade - como uma política de governo - o que se pode inferir a Municipal de Atendimento Socioeducativo em Meio Aberto, independente de qual seja a pessoa/liderança política-partidária que esteja na gestão administrativa.

Em decorrência dessa postura política assumida, percebe-se que ainda de forma iniciante tem ocorrido encontro entre poderes (executivo e o poder judiciário da capital, sob a estruturação de seminário transdisciplinar) para se pensar a questão fenomenológica das medidas socioeducativas em meio aberto.

No entanto, ainda que se tenha todos esses avanços designados pelos marcos regulatórios da política geral de atendimento da criança e do adolescente, assegurados no âmbito da proposta de governo, pelos trabalhos acadêmicos realizados foi possível perceber que no cotidiano da administração pública ainda existem dificuldades das condutas corriqueiras estarem relacionadas ao novo paradigma de atendimento. As práticas do estado, relacionadas à medida socioeducativa ainda estão voltadas para práticas que se distanciam da dimensão educativa, necessária para a formação pessoal, como direito subjetivo, direito público fundamental.

Isso faz com que esses descompassos fragilizem a proposta que busca expansão e consolidação. Conhecer essas limitações e atuar de forma a superá-las, com vista a alcançar uma proposta fundada na formação humana, seria algo de ganho social relevante, necessário e imprescindível para toda a coletividade social, que precisa assegurar à criança e ao adolescente a convivência comunitária educativa, sob as premissas da Proteção Integral.

\section{Referências}

AZEVEDO, Monique Silva de; SUÇÃES, Nathália Amaro. A municipalização das medidas socioeducativas em meio aberto no Estado do Rio de Janeiro. 2011. Trabalho de Conclusão de Curso (Graduação) Serviço Social, Universidade Federal do Rio de Janeiro, Rio de Janeiro, 2011.

BRASIL. Sistema Nacional de Atendimento Socieducativo - SINASE. Presidência da República. Secretaria Especial dos Direitos Humanos. Brasília DF: CONANDA, 2006.

BRITO, Leila Maria Torraca de. (Coord.) Jovens em conflito com a lei: a contribuição da universidade ao sistema socieducativo. Rio de Janeiro: EdUERJ, 2000.

BUCCI, Maria Paula Dallari. (Org.) Políticas públicas: reflexões sobre o conceito jurídico. São Paulo: Saraiva, 2006.

CHAUÍ, Marilena. A não-violência do brasileiro, um mito interessantíssimo. Almanaque: Cadernos de Literatura e Ensaio. Brasiliense, Brasília, n. 11, 1980.

COCURUTTO, Ailton. Os princípios da dignidade da pessoa humana e a inclusão social. São Paulo: Malheiros, 2008.

CURY, Muniz .(Coord.) Estatuto da Criança e do Adolescente comentado: comentários jurídicos e sociais. 7. ed. São Paulo: Malheiros.

FRASER, Nancy. Reconhecimento sem ética? Lua Nova, São Paulo, v. 70, p. 101-138. 2007.

FREIRE, Paulo. Pedagogia da autonomia: saberes necessários à prática educativa. São Paulo: Paz e Terra, 1996.

LEAL, Roberta Martins dos Santos. Municipalização das medidas socioeducativas em meio aberto: efetivando direitos de adolescentes em conflito com a lei. 2011. Monografia (Pós Graduação Lato) - Instituto A Vez do Mestre, Universidade Candido Mendes, Rio de Janeiro, 2011.

MANACORDA, Mario Alighiero. Marx e a pedagogia moderna. São Paulo: Cortez: Autores Associados, 1991.

MENESES, Elcio Resmini. Medidas socieducativas: uma reflexão jurídico-pedagógica. Porto Alegre: Livraria do Advogado, 2008.

MENEZES, Thaís Vargas. A responsabilidade do adolescente autor de ato infraccional: ampliando o horizonte a partir da proposta socioeducativa. 
2012. 131 f. Dissertação (Mestrado em Psicologia) Universidade Federal do Rio de Janeiro, Rio de Janeiro, 2012.

SOUZA, Jessé. A ralé brasileira: quem é e como vive. Belo Horizonte: UFMG, 2011.

WACQUANT, LoÏc. Forjando o estado neoliberal: trabalho social, regime prisional e insegurança social. In: BATISTA, Vera M. (Org.) LoÏc Wacquant e a questão penal no capitalismo neoliberal. Rio de Janeiro: Revan, 2012. 